\title{
La educación como espacio en disputa entre el campesinado y el agronegocio
}

\author{
Constanza María Urdampilleta ${ }^{1}{ }^{(0)}$, Mariana Totino $^{(1)}$, Raúl Esteban Ithuralde \\ Universidad Nacional de Santiago del Estero; Universidad Nacional de San Martin; Universidad Nacional de Santiago del Estero; CONICET - Argentina
}

Autor de correspondencia: ${ }^{1}$ coniurdampilleta@gmail.com Recibido: 15 de julio de 2020 Revisado: 02 de septiembre de 2020 Aprobado: 06 de enero de 2021 Publicado: 12 de abril de 2021

\section{Resumen}

En este texto presentamos un trabajo de indagación sobre las formas en que el conflicto ambiental entre el campesinado y el modelo del agronegocio en Santiago del Estero, Argentina, se expresa en el campo educativo. Para llevar adelante este estudio de corte cualitativo, realizamos primero entrevistas semiestructuradas y observaciones participantes en reuniones y talleres en comunidades campesinas de las sierras de Guasayán. Luego revisamos documentos de organizaciones campesinas de la provincia de Santiago del Estero. Después se realizaron ciclos sucesivos de codificación abierta y axial. Los resultados se estructuraron en los siguientes ejes conceptuales: (1) sistema escolar en los territorios campesinos, (2) aprendizaje por participación en las comunidades y en el movimiento y (3) Escuela de Agroecología. La conclusión es que el campo educativo es uno de los contextos de disputa entre el campesinado y el agronegocio en la lucha del primero por su propia (re)existencia. Resaltamos así la importancia de mirar no solo cómo se representan los conflictos ambientales en el sistema educativo, sino también las prácticas de agentes educativos en dichos conflictos.

Palabras clave: educación ambiental, conflicto social, clase campesina 


\title{
Education as a disputed field between peasants and agribusinesses
}

\begin{abstract}
In this article we present an enquiry on the ways in which the environmental conflict between the peasants and the agribusiness model in Santiago delEstero, Argentina, isexpressed in the field of education. In order to carry out this qualitative study, we first conducted semistructured interviews and participant observations in meetings and workshops in peasant communities in the mountains of Guasayán. We then reviewed documents from peasant organizations in the province of Santiago del Estero. This was followed by successive cycles of open and axial analysis. The results were structured along the following conceptual axes: (1) school system in peasant territories, (2) learning by participation in communities and in the movement and (3) Agroecology School. The conclusion is that the field of education is one of the contexts of dispute between the peasants and agribusiness in the former's struggle for its own (re)existence. We thus highlight the importance of looking not only at how environmental conflicts are represented in the educational system, but also at the practices of educational agents in such conflicts.
\end{abstract}

Keywords: environmental education, social conflict, peasant class

\section{A educação como um espaço em disputa entre camponeses e agronegócios}

\section{Resumo}

Neste artigo apresentamos um trabalho de pesquisa sobre as formas como o conflito ambiental entre os camponeses e o modelo do agronegócio em Santiago del Estero, Argentina, se expressa no campo educacional. Para realizar este estudo qualitativo, primeiro realizamos entrevistas semiestruturadas e observações participantes em reuniões e oficinas em comunidades camponesas nas serras de Guasayán. Em seguida, revisamos documentos de organizações camponesas da província de Santiago del Estero. Posteriormente, ciclos sucessivos de codificação aberta e axial foram realizados. Os resultados foram estruturados ao longo dos seguintes eixos conceituais: (1) sistema escolar em territórios camponeses, (2) aprendizagem na participação nas comunidades e no movimento, e (3) Escola de Agroecologia. A conclusão é que o campo educacional é um dos contextos de disputa entre o campesinato e o agronegócio na luta do primeiro por sua própria (re)existência. Desta forma, destacamos a importância de olhar não apenas para a forma como os conflitos ambientais são representados no sistema educacional, mas também para as práticas dos agentes educacionais em tais conflitos.

Palavras-chave: educação ambiental, conflito social, classe camponesa 
En América Latina, al calor de las luchas sociales, surgieron en los años 60 y 70 corrientes de pensamiento pedagógico propias con horizontes emancipadores, en particular la educación popular. Sus principios de producción de conocimiento -en oposición a la colonización intelectual imperante-, de una educación liberadora/emancipadora y dialógica, de recreación de saberes y culturas populares, y de la creación como proceso imprescindible para la emancipación son ineludibles en cualquier experiencia educativa crítica. La educación ambiental [EA], que en sus inicios tenía como principales debates la cuestión de la complejidad, la interdisciplina, la transversalidad y su pertenencia al área de ciencias naturales o ciencias sociales, adquiere un carácter crítico a partir del diálogo con estas corrientes pedagógicas críticas latinoamericanas y con el pensamiento ambiental latinoamericano. Así, la EA latinoamericana se posiciona de frente al modelo de desarrollo hegemónico del sistema capitalista (González, 2012) y promueve un diálogo con los movimientos sociales para fortalecer su propia construcción.

En el sistema educativo argentino, para construir una EA contextualizada, se ha recurrido a tres conceptos, que se proponen como ejes estructuradores de la enseñanza: problemáticas sociocientíficas (Massarini \& Schnek, 2015), problemáticas ambientales (Defago et al., 2012) y conflictos ambientales (Canciani \& Telias, 2013). En este último caso, se toman conflictos ambientales para organizar, a través de su estudio -análisis y problematización-, el trabajo alrededor de los conceptos, teorías y herramientas que se tienen como horizonte de aprendizaje en el espacio educativo. Por otra parte, en los territorios hay educadores ambientales que desarrollan la EA por fuera de ámbitos formales, e incluso fuera de espacios educativos, con lo que construyen una praxis crítica que se encuentra mayormente sin sistematizar (Corbetta \& Sessano, 2018).

En particular, en el ámbito rural donde se desarrolla este estudio, la escuela es un lugar importante de socialización y de construcción de ciudadanía. Allí actualmente se encuentran distintas interpretaciones de los conflictos y transformaciones territoriales (Griggio, 2018; Plencovich et al., 2011). A pesar de las particularidades territoriales, según la Ley Nacional de Educación (Congreso de la Nación Argentina, 2006), la educación rural es una modalidad educativa en la Argentina, pero esto no significa un plan de estudios diferente, porque el sistema educativo nacional se basa en la idea de que la educación básica debe ser una educación común para garantizar la libre circulación de habitantes de una zona a otra. El carácter de la modalidad se adecua a la logística - formas de transporte, comunicación y matrícula- (Plencovich et al., 2011). A pesar de ser obligatorio, hacia 2010 el 40 \% de los jóvenes de ámbitos rurales aún no tenía acceso a la educación secundaria (Plencovich et al., 2011).

Este trabajo se contextualiza en el medio rural de Santiago del Estero, Argentina, donde se fundó en 1990 el Movimiento Campesino de Santiago del Estero [MoCaSE], formado por cuatro organizaciones campesinas de la provincia. En su acta fundacional se sostiene:

Desde sus comienzos, el MoCaSE asumió como estrategia central la lucha por la tenencia de la tierra y por las condiciones de vida de las familias campesinas. El problema generalizado de tenencia precaria de la tierra por parte de los campesinos había generado un histórico proceso de "desalojos silenciosos" en la medida en que no había conciencia sobre el derecho de posesión veinteñal y a la vez no estaban dadas las condiciones mínimas de organización 
para que las presentaciones ante la justicia o los reclamos ante el poder político tuvieran alguna posibilidad de éxito. (MoCaSE-VC, 2016, p. 170)

A medida que la organización fue creciendo y madurando, comenzó a desarrollar estrategias en diversos ámbitos: formación, producción, salud, entre otros. Luego de años de tensiones internas, en 2001 el MoCaSE se dividió en dos sectores: el MoCaSEVía Campesina [MoCaSE-VC] - por su incorporación a esta organización global-y el MoCaSE -o MoCaSE histórico- (Ashpa Sumaj, 2012; MoCaSE-VC, 2016). En esta última organización, donde se encuadraron las comunidades campesinas de las sierras de Guasayán -ubicadas en el centro oeste de la provincia-, fueron realizadas las entrevistas y observaciones para este estudio, luego de la ruptura. Desde 2019, estas comunidades están participando activamente en un proceso de reunificación entre ambos movimientos.

Consideramos los territorios como construcciones sociales en disputa que abarcan distintas dimensiones de espacio. La educación, las identidades y los modos de concebir las relaciones entre las sociedades y la naturaleza forman parte de las luchas territoriales (Corbetta \& Karol, 2015). A la vez, según Gramsci (2015), entendemos que lo pedagógico no se restringe solamente a instituciones escolares o espacios educativos, sino que permea toda la práctica de las organizaciones sociales y políticas (Michi, 2010). Coincidimos así con Matteo (2015) en que integrantes de diversos movimientos sociales que realizan trabajo de base organizativo actúan como educadores populares. En el caso que dichos trabajos de base involucren una dimensión ambiental - como ocurre en organizaciones ambientalistas, movimientos campesinos, organizaciones de pueblos originarios, entre otros-, estas personas estarían actuando como educadores populares ambientales. Palumbo (2016) sostiene que existen tres formas principales de la actuación pedagógica de los movimientos sociales:

En la forma-escuela otra, la forma-taller y la forma movimiento. La primera — con aires de familia y alternativa a su vez a la escuela moderna - responde a las experiencias construidas por fuera o en los márgenes del sistema educativo formal que adoptan mayores grados de sistematicidad, regularidad y planificación en la tarea pedagógica, como jardines comunitarios, primarias populares de adultos y bachilleratos populares para jóvenes y adultos en movimientos populares urbanos, y escuelas y universidad campesinas para jóvenes y adultos en movimientos populares indígena-campesinos. (p. 3)

En este trabajo analizamos las múltiples formas en que lo educativo forma parte de los conflictos ambientales que se sostienen entre el campesinado agrupado en el MoCaSE, Argentina, y el modelo del agronegocio (Gras \& Zorzoli, 2019). No se busca conocer cómo se abordan los conflictos ambientales en el campo educativo, sino que el objetivo es comprender cómo se encarna el aspecto pedagógico en una serie de conflictos ambientales, debido a las acciones que configura el aprendizaje para la (re)existencia en las comunidades campesinas por fuera del sistema escolar como acciones de agentes que responden al modelo del agronegocio (Michi \& Matteo, 2009). El supuesto que guía a este objetivo, coincidente con estudios anteriores, es que lo educativo desborda a lo escolar y que hay múltiples perspectivas de la EA en disputa en los territorios, desarrolladas en diferentes espacios y por agentes - muchas veces-con intereses antagónicos. 


\section{Metodología}

Este trabajo es de corte cualitativo, exploratorio y descriptivo. Lo presentado aquí forma parte de un proyecto más amplio sobre las formas de producción de las comunidades campesinas en las sierras de Guasayán, Santiago del Estero, Argentina.

Se realizaron en un principio: (a) entrevistas semiestructuradas, en las comunidades de Villa Guasayán, Las Juntas y San Ramón, a 46 familias en sus propias viviendas, en 2017 y 2018; (b) observaciones participantes de la cotidianidad de cinco familias de las comunidades; de un encuentro de aproximadamente 25 jóvenes de las comunidades de las sierras de Guasayán -2018-; de reuniones y talleres de la Mesa Regional de Tierra ChoyaGuasayán -2017-2019-, donde participan generalmente delegades ${ }^{1}$ de las comunidades de base, jóvenes de las mismas y personal técnico de organizaciones compañeras - con una participación variable de entre 7 y 12 personas, que llegaba a 20 o más cuando se organizan talleres-.

Posteriormente, para complementar los datos producidos en el campo, se construyó un corpus documental a partir de las producciones del grupo de Memoria Histórica del MoCaSE-VC, un equipo de dicha organización que se ha ocupado de recuperar la memoria colectiva de las comunidades campesinas nucleadas en la misma y de producir libros a partir de su sistematización (Ashpa Sumaj, 2012; Ferreyra, 2012; MoCaSE-VC, 2016, 2017, 2018). Este corpus sirvió para ampliar la experiencia de las comunidades de Guasayán con relatos provenientes del campesinado de diferentes departamentos del resto de la provincia de Santiago del Estero.

Se realizaron a posteriori ciclos sucesivos de codificación abierta y axial sobre los datos obtenidos a partir de las entrevistas y las observaciones. Así, se desarrolló una generación conceptual (Strauss \& Corbin, 2002) y se llegó a un punto de saturación teórica de la muestra. Se realizó una triangulación de los datos provenientes de las entrevistas, de las observaciones y del corpus documental construido.

\section{Resultados}

Los resultados están organizados en tres ejes: (1) sistema escolar en los territorios campesinos, (2) aprendizaje por participación en las comunidades y en el movimiento y (3) Escuela de Agroecología. Las personas entrevistadas se identifican, para mantener el anonimato, como E1, E2 ... sucesivamente.

\section{El sistema escolar en los territorios campesinos}

El campesinado de las sierras de Guasayán reconoce diversos problemas relacionados con el sistema educativo: la inexistencia de establecimientos de ciertos niveles, la lejanía de los existentes y una enseñanza disociada de la realidad campesina. En varias de las comunidades relevadas no existen establecimientos de nivel inicial, cuya asistencia es obligatoria en Argentina. Es un requisito para el cobro de ciertas asignaciones sociales - como la asignación universal por hijo-. En una entrevista a una campesina, nos relataban:

— Entrevistadora: ¿Y les dijeron que sí se puede poner el jardín?

1 Optamos por utilizar la letra e para visibilizar el amplio abanico de orientaciones de género que no pueden ser contenidas en la dicotomía mujer/varón. 
—E1: Y, está ahí el supervisor, que ya va a ver, a ver qué nos dice, porque también es algo importante porque hay muchos chiquitos.

— Entrevistadora: $\mathrm{Y}$ ustedes necesitan la firma de la directora para cobrar la asignación por hijo, ¿no?

- E1: Claro, que participe por lo menos tres veces a la semana.

- Entrevistadora: Es un problema eso para ustedes.

- E1: Es un verdadero problema.

En nuestras entrevistas, las personas comentan que existen suficientes establecimientos de nivel primario, pero no de nivel secundario. Estos últimos están en la ciudad más cercana, San Pedro de Guasayán y también en Guampacha - fundado recientemente, a partir de un programa provincial para extender la escolaridad secundaria en zonas rurales-, pero que dista entre 10 y 25 kilómetros de las comunidades relevadas.

- Entrevistadora: ¿Es posible que el secundario llegue?

- E2: Ojalá, están en eso. Porque hay muchos chicos que lamentablemente han dejado de estudiar porque no tienen posibilidad de ir a otro lado. Hay muchos chicos de acá que van a Guampacha.

- Entrevistadora: ¿Qué distancia hay a Guampacha?

—E2: 20, $25 \mathrm{~km}$. Mi sobrina va ahí al secundario, por ahí le toca el doble turno y se va a la mañana y se queda. Van en moto los chicos, y es un peligro también porque no sabés qué le puede pasar en la ruta.

- Entrevistadora: $\mathrm{Y}$ es un gasto.

— E2: Y sí. Teniendo un colegio aquí que tiene primaria a la mañana y a la tarde está vacío.

—E3: Sí, ellos iban a la escuela en Guampacha, en bicicleta. Sacaban leche. Hacían el queso, de las cabras. Por ahí venía mi patrón, el dueño del coto, y los alcanzaba en la camioneta, porque ya los conocía - nos había dicho que durante un tiempo él trabajó de peón para el coto de caza-.

Para disminuir las distancias para acceder a las escuelas, la educación secundaria se extiende con modalidad de agrupamiento, que implica la itinerancia de docentes por distintas comunidades en las cuales sus estudiantes, a su vez, acuden a una sede que las centraliza. En la reunión de Mesa Regional de Tierra Choya-Guasayán, se pone en duda la efectividad de esta modalidad y la existencia de otras propuestas como la alternancia.

- E4: La sede original es Rodeo, allá cerca de Villa la Punta. Después se lo ha desdoblado y se lo ha puesto en Guampacha, porque no daba. Era muy lejos la distancia. Guampacha tiene concentrado lo del resto de los alumnos de las otras localidades. Esa es la función de esos agrupamientos. En otros lados está la cuestión de la itinerancia y permanencia. [...] tienen sus pros y sus contras esos agrupamientos porque hay muchos profesores que han abandonado por una cuestión de costos o porque no les da la movilidad. Tienen que ir de una escuela a otra para juntar horas porque también es verdad que no les alcanzaba. Pero bueno, sigue funcionando. Esta es la segunda promoción, la que sale este año. Son jóvenes que están saliendo y no están siguiendo nada.

Una cuestión que se repite en las entrevistas es que quienes salen a estudiar - a la capital provincial o localidades cercanas- no vuelven a las comunidades. Ya se quedan allí, por lo 
cual esta configuración del sistema educativo promueve la histórica expulsión de personas del mundo rural santiagueño.

—E5: Sí, por ejemplo, una plaza para los chicos, un mini hospital, la secundaria, para que los chicos no se vayan a estudiar en otro lado.

- Entrevistadora: ¿Están quedando menos chicos acá porque se van?

— E5: Sí, se van muchos jóvenes.

De esta manera, el sistema educativo en las áreas rurales santiagueñas incumple la garantía estatal al derecho a la educación por dos motivos: primero, por la inexistencia de instituciones en las comunidades - hay en muy pocos lugares establecimientos de nivel inicial y de nivel secundario, por lo que se deben recorrer grandes distancias, con los costos y peligros que ello conlleva, y la absoluta inexistencia del nivel superior en ámbitos rurales-; y segundo, la enseñanza privilegia saberes urbanos y de la agricultura industrial por sobre saberes del modo de vida campesino.

En otras zonas de la provincia, campesines organizades en el MoCaSE-VC reflexionaron sobre esta cuestión:

Paulo: Por ahí en la escuela nunca no nos han enseñado los derechos que nos corresponden y cuando uno va conociendo eso, es como que se va sintiendo más seguro, podés discutir y sabés que nadie te está jodiendo, porque uno conoce. Y nosotros, dentro del Movimiento, hemos encontrado muchos valores, como nuestra propia identidad como pueblo. Que a veces nosotros nos parecía que no era nuestro origen, como que no lo aceptábamos, porque en la escuela siempre hablaban del indígena que era el malo; más identificados como los indios, los brutos, los negros, los rebeldes. (MoCaSE-VC, 2017, p. 18)

"Beco: El tema es que se ha vivido muchos años bajo represión, nadie te enseñaba nada, la escuela nunca te enseñaba, al contrario, te han hecho perder la cultura, la lengua, todo" (MoCaSE-VC, 2017, p. 41).

El sistema educativo históricamente ha formado parte de estrategias estatales que pretendieron erosionar la cultura campesina e indígena en la provincia. Hemos escuchado relatos de cómo les estudiantes en la primaria eran castigades si se comunicaban en su lengua materna, la quichua. Además, el campesinado ha denunciado la histórica complicidad de parte del personal docente con empresaries que buscan desalojarles. Por ejemplo, en el caso del asesinato de Cristian Ferreyra a manos de un sicario que realizaba trabajos para el empresario Jorge Ciccioli - que buscaba quedarse con las tierras de la comunidad-, en 2011, las armas del grupo parapolicial eran guardadas en el propio establecimiento escolar primario adonde asistían les niñes de la comunidad:

Josefa: $\mathrm{Y}$ ayer, fueron mis hijos a la escuela y le dijo el maestro: "Ha muerto Cachito", "Sî" le dijo el chico mío, "Ha muerto, lo han muerto", "Y bueno, eso lo han mandado matar los de MoCASE" dice, "y yo no quiero decir nada porque van a decir que un chico no puede." Y dice: "Decile a Chiquín que se retire un poquito del MoCaSE que también lo van a matar a él, lo va a mandar a matar el MoCaSE”. El maestro dice eso... a los chicos.

José: Yo no sé cómo se podrá hacer para hacerlo sacar.

Estela: Nunca, nunca. Ellos siempre en contra. 
José: Y el maestro vivía reunido con Ciccioli cuando él venía, porque Ciccioli venía todos los días. (Ferreyra, 2012, p. 44)

Así, en este territorio, el maestro - al usar los propios títulos escolares que el mismo sistema emite- moviliza sus capitales otorgados por su rol, dota de legitimidad las estrategias de les empresaries, e incluso, les brinda ayudas materiales - como espacios de guardado de las armas-. De esta forma, el maestro, legitima que quienes son dueños de las tierras son les empresaries con papeles de dudosa legalidad, frente al campesinado que sostiene una ocupación ancestral de las tierras, lo cual le confiere un derecho a la propiedad en términos del Código Civil y Comercial argentino (Congreso de la Nación Argentina, 2014). Esta legitimación diferencial de quiénes tienen derecho a la propiedad es también un ejercicio de un rol pedagógico desde su práctica (Gramsci, 2015; Michi, 2010), que en lo ambiental podemos asociar con formas socialmente válidas de relación con la tierra y la naturaleza - en este caso, las del empresariado-, lo que podemos pensar como una EA en acto.

En otros casos - los menos-, militantes del MoCaSE han tejido alianzas con agentes educativos, para realizar actividades en los predios escolares y organizar acciones conjuntas contra las fumigaciones con agrotóxicos en las comunidades. Incluso varies miembres del movimiento son docentes. Esto muestra que no se descarta a estos espacios como lugares de resistencia, disputa y creación, pero son espacios con un alto grado de control y disciplinamiento por parte del nivel central del Ministerio de Educación de la provincia. Han llegado incluso a amenazar con suspender o trasladar a docentes que manifestaron públicamente que las fumigaciones estaban generando daños en la salud de las poblaciones.

En la Mesa Regional de Tierras Choya-Guasayán, en 2018, se discutió también la problemática de les jóvenes y se pusieron en común distintos aspectos que les preocupan. En todo momento la educación jugó un rol importante. Las preocupaciones incluyeron: el bajo porcentaje de jóvenes que asisten a la educación secundaria y superior y que completan sus estudios; el hecho de que les jóvenes no regresan a las comunidades cuando salen a estudiar; pero lo más preocupante es la falta de una propuesta de modo de vida para les jóvenes por parte de las instituciones estatales que conforman el territorio y cómo esto se articula con las prácticas familiares.

- E6: Volviendo sobre lo de que los chicos estudian y se van lejos [...] Si vos quieres estudiar e irse son cosas tuyas, si quieres estudiar, aprender y volcarlo a tus parientes o los mismos chicos de la escuela, pero no desaprovechar eso, porque si todo lo que aprendes te vas a estudiar a EE. UU., a mí no me sirve. No les sirve a los chicos. No le sirve a nadie. [...] 40 chicos han empezado la secundaria con mi hijo. Han terminado 4. De los 4 él solo está yendo a la universidad.

- E4: Todos estamos enamorados de nuestras raíces, pero también nos han metido en la cabeza que teníamos que salir porque aquí adentro no hay nada para hacer. ¿Cómo desandar eso? Es clave para arrancar eso.

—E7: Las escuelas son las que tampoco están haciendo mucho.

—E4: No, ellos tienen la idea también: "los chicos no tienen nada para hacer". Y también es real. Porque nadie se está poniendo realmente en la cabeza $-\mathrm{y}$ estamos hablando de autoridades ya, el comisionado-. Nadie tiene un objetivo de qué van a hacer los jóvenes 
en las localidades. Hoy no tienen fuentes de trabajo más que un plan, que es una miseria. Esa es la expectativa que tienen. Por eso, las instituciones tienen que darse el debate de integración de los jóvenes porque, si no, los chicos tienen que salir a trabajar y están saliendo a trabajar otra vez de nuevo dejando la escuela.

En el sistema educativo se estarían construyendo así ciertos modelos-imágenes del desarrollo: una vida urbana, con producciones para la venta en el mercado, sin reconocimiento de las diversidades, que desvaloriza la vida campesina, como bien ha sido registrado (Michi, 2010; Michi \& Matteo, 2009). Por un lado, la misma ausencia del sistema educativo - al menos en varios de sus niveles- en vastas áreas rurales es una muestra en sí misma del posicionamiento a favor de la vida urbana. La necesidad de las personas de mudarse a pueblos o ciudades o de trasladarse diariamente por grandes distancias para poder acceder al derecho a la educación es también una forma pedagógica del Estado. Además, suelen migrar definitivamente, lo que es entonces una vía que promueve la migración del campo a la ciudad.

Más aún, en varios casos, docentes del sistema educativo son aliades de empresaries que buscan desalojar a campesines que tienen la posesión ancestral de la tierra, como se observa en el caso de Cristian Ferreyra: el maestro de la comunidad utiliza su lugar de legitimidad para asegurar que la tierra no le pertenece a les campesines y además colabora en las acciones de represión parapolicial - mostrando un amparo estatal a grupos supuestamente fuera de la ley-.

La disputa por la arbitrariedad cultural en los procesos de formación de las personas campesinas - qué se enseña, cómo se enseña, para qué se enseña, quién enseña, cómo enseña- excede la lucha por el currículo en todos sus niveles de concreción (Alba, 1998). No hay solamente una disputa por la selección de contenidos, sino incluso por la figura de quién legítimamente tiene el saber. Como mencionaba una campesina, les maestres en las escuelas o les técniques en las capacitaciones de diversas instituciones estatales u organizaciones no gubernamentales pueden tener un saber construido desde la teoría, pero que finalmente, al no estar situado en el territorio, es incorrecto, en el sentido de que no se ajusta a la realidad social, cultural, económica, geográfica, geológica y ecológica del campesinado de las sierras de Guasayán. Les campesines se constituirían así en actores con un saber legítimo sobre los procesos productivos en su propio territorio. Se están disputando entonces las formas de construcción de un capital, las formas de legitimación social de ese capital, en este caso un capital cultural, y las mismas reglas de juego del campo, de cómo acceder a las posiciones consagradas en el mismo (Bourdieu, 2012). El caso de Cristian Ferreyra es ilustrativo: no solo hay un conflicto por la enseñanza en la escuela, sino por el accionar social del maestro en ese territorio, por sus alianzas con el empresariado que, a través de maniobras que incluyen la corrupción y la violencia física y simbólica, busca desalojar a las personas de sus tierras (Ferreyra, 2012). Se lucha así por el uso que hace el personal docente de su posición como agente educativo estatal en los territorios campesinos en relación con los conflictos ambientales, en particular los de tierra, es decir, por la utilización de ese capital consagrado en el campo educativo en un espacio social más amplio.

El rol de les agentes educatives opera por acción, pero también por omisión, por la falta de ejercicio de la educación para acompañar el desarrollo personal de les jóvenes para la 
vida en el monte chaqueño. Al reproducir la idea de que les jóvenes en el campo no tienen futuro, niegan así la producción y reproducción que sostienen y construyen cotidianamente las familias de sus estudiantes. Desde los niveles centrales, utilizan la coerción para desarticular toda forma de resistencia. En ese sentido se pueden pensar como procesos de desterritorialización, en su doble despojo: físico y simbólico (Giraldo, 2018).

\section{Aprendizaje por participación en las comunidades y en el movimiento}

La matriz cultural campesina también tiene representaciones sobre cómo se aprende y/o se conoce:

— E8: Aquí el chico desde que se para solo ya va al chiquero a jugar, o con los cabritos.

El aprendizaje de les niñes, entonces, sucede en las comunidades dentro de un proceso que se puede pensar como participación comunitaria intencionada (Rogoff, 1997). Les niñes participan de la vida de la comunidad, de sus actividades productivas, sociales y políticas, e internalizan herramientas o instrumentos culturales a partir de realizar regularmente tareas de forma coordinada con les adultes - es decir, en donde se pone en juego la intersubjetividad para llegar a metas comunes, metas de las cuales les niñes también tienen alto grado de participación en su construcción-.

También les adultes siguen aprendiendo y creando conocimiento de la misma forma. Así, los saberes campesinos, circulan en la comunidad y crean un corpus de conocimiento en la memoria colectiva (Baraona, 1987). De padres y madres a hijes, entre parientes y entre vecines, la circulación de saberes es densa y abundante, de forma que los conocimientos no se pierdan. Este corpus de conocimientos contiene una infinidad de técnicas y saberes, que serán utilizadas de acuerdo con el contexto, con su facilidad y con los gustos y deseos de cada sujeto.

La Mesa de Tierras en sus debates pone en valor la importancia de estas prácticas:

- E4: No sé cuántos jóvenes hacen el trabajo que hacíamos todas las familias campesinas. Yo puedo decir que mis hijos hacen trabajos en la casa de la vida campesina, porque yo se los estoy inculcando, porque quiero que mis hijos sigan valorando la tierra que desde padres y abuelos de la misma manera [sic]. No sé si el resto lo hacen, hay chicos que ya no hacen las tareas de campo. No saben diferenciar un quebracho de un algarrobo blanco. Viven en el campo como jóvenes urbanos. [...] Hay que recuperar el valor del campo.

La problemática educativa se evidencia en los aglomerados intermedios donde las familias han ido dejando sus prácticas productivas. Como expresa un campesino:

—E6: Al político no le interesa [...] Y ese grupo de gente le han quitado la tierra los padres no tienen a donde vivir, porque les han engañado, los han sacado del campo, los han metido ahí y les han dicho: "aquí van a vivir mejor, van a tener agua, van a tener luz".

Además de los aprendizajes propios de la participación en sus familias -el grupo de socialización más cercano-, también aprenden al formar parte del movimiento social en sus diferentes formas - MoCaSE, Mesa Zonal de Tierra de Guasayán-. Esta participación tiene una dimensión pedagógica fundamental en la construcción de herramientas culturales y de las identidades de las personas que la conforman (Michi, 2010), no solo en espacios propiamente formativos, o incluso en espacios de reunión, sino que el posicionarse en 
un conflicto de tierra y pararse frente a empresaries que buscan desalojarles son también situaciones que llevan a profundos aprendizajes. Una campesina, por ejemplo, nos cuenta de su propio proceso:

— Entrevistadora: Igual tenés una personalidad muy segura. Debe haber gente a la que le harán creer que ellos saben más, ¿no?

- E8: A nosotros nos pasaba eso antes de que empezáramos a participar. Me sentía tan identificada cuando leía el librito [de la Vía Campesina] donde decía que es otra cosa cuando uno ya está organizado, porque va entendiendo, va conociendo. [...] Aquel que no sabe nada empieza por el interés propio. Lo que les tienen que enseñar es al interés propio hacerlo común, para que la cosa marche ¿entiendes? Y eso nos costó unas cuantas capacitaciones.

- Entrevistadora: ¿Entonces antes ustedes no funcionaban como comunidad?

— E8: ¡No! Cada chancho a su rancho. Pero sí había otras cosas que nosotros fuimos perdiendo, por ejemplo, las mingas. Eso se perdió y no lo podemos recuperar, porque esta porquería [la tele] es la que nos pierde, nos separa [...] Antes, cuando no había esto, por ejemplo, llegaba la noche y te ibas a la casa del vecino a tomar mate. Los chicos jugaban si era noche de luna. Las mingas eran los domingos. Todos se juntaban. Iban a trabajar o, si tenían que sembrar, sembraban entre todos. Primero sembraban a uno, después al otro. Igual, cuando uno carneaba una cabra, le prestaba una parte al otro. Eso se perdió. [...] Lo que ayer te quería contar era cómo habían nacido las comunidades aquí. El cura nos presentó la Biblia y la primera lectura que nos leyó era sobre las primeras comunidades. Cómo trabajaban ellos y se repartían de acuerdo a las necesidades que cada uno tenía. ¿Y por qué nosotros cada día un poquito más no podíamos hacer lo que hacían las primeras comunidades? De compartir con otros, lo poquito que sea.

La organización, el movimiento, se configura como un espacio para recuperar algunos saberes perdidos, o al menos para revalorizarlos, así como para una transformación en la autoestima de las personas. El movimiento también organiza, junto a otras organizaciones o instituciones públicas, espacios formativos, en particular sobre lo productivo:

- E9: Estaba como cansada la tierra. Por ejemplo, esto que ahora nos enseñan a hacer el abono, eso sería bueno [el taller de BePe]. Porque antes uno lo sembraba así nomás. Y la chacra se hacía chiquita. Dicen que eran muchos años que se venía sembrando y sembrando.

— Entrevistadora: Y en ese cerco viejo ¿cuántos años habían sembrado?

— E9: Y, era de mis abuelos.

- Entrevistadora: Entonces ¿hace varios años que ustedes no siembran?

—E10: Y sí, hará como 4 años.

La organización genera, de esta manera, una formación hacia sus participantes sobre herramientas para una producción agropecuaria sustentable, situada no solo en el ecosistema de las sierras de Guasayán, sino en el territorio de las comunidades campesinas. La formación parte de un diagnóstico de la propia comunidad campesina, sobre el agotamiento del suelo de su cerco, del cansancio de esa tierra, debido a los muchos años de uso. Es decir, hay una integración entre saberes locales sobre el territorio y saberes técnicos que provienen de afuera (Baraona, 1987). 
Con respecto a observaciones anteriores, para que esta síntesis sea posible, es necesario que el nuevo conocimiento que se incorpora al corpus sea compatible, para poder dar explicaciones relacionadas con este (Díaz et al., 2005). En nuestro caso, el comenzar a abonar la tierra en estos territorios se articula con un saber local acerca de que la tierra se cansa luego de muchos años de uso y que entonces hay que hacer nuevos cercos para cultivar. Esto implica desmontar pequeñas superficies de tierra y perder entonces superficie boscosa y, además, una importante inversión de tiempo de trabajo - en el desmonte, en cercar el espacio, en acondicionar la tierra para poder ser sembrada-, por lo cual la posibilidad de poder mantener la fertilidad del suelo adquiere ventajas para el campesinado. Un campesino de Las Juntas contaba cómo había construido una acequia para llevar agua a su cerco junto al abono - al introducir en el agua la materia fecal de sus animales-, como una forma de evitar este cansancio de la tierra.

La apropiación de saberes externos no se realiza como copia, sino que se reconstruye en diálogo con los propios saberes. Una campesina nos cuenta sobre una capacitación en el marco de un plan de implantación de algarrobos:

- E8: Vinieron, capacitaron, dieron una charla para explicarnos cómo era, las ventajas, qué era lo que requerían, cuál iba a ser nuestro aporte. Yo he hecho lo que he querido, por eso he demorado más [risas]. A mí me decían "plantá de esta manera". Y no, yo quería plantar como yo quería. Cinco veces he sembrado.

- Entrevistadora: ¿Por qué? ¿Vos pensabas que era mejor tu manera?

- E8: Claro.

- Entrevistadora: ¿Y tenías razón?

—E8: En parte sí y en parte no. Porque ellos, por ejemplo, te enseñaban a apretar así la tierra y la semillita taparla poquitito. Pero con los soles tan fuertes, cuando salía la plantita, ipuf! Se quemaba. Yo cavaba un poquito con el dedo y la enterraba. Esa demoraba más. La que estaba encimita salía en 3 o 4 días, pero, así como salía, moría. La otra demoraba un poco más, pero no se moría.

Su método, aunque más lento, aseguraba una mayor supervivencia de sus plantas.

Entendemos que estos procesos de participación intencional comunitaria - tomados en sentido amplio y no solo ligados a lo productivo- no solo tienen como intención la internalización de ciertas herramientas e instrumentos culturales que permitirán a les individues resolver ciertas tareas -más o menos esenciales para su supervivencia en el monte-, sino que son también una forma de producción y reproducción de la cultura campesina santiagueña. En esta construcción cultural e identitaria, la ruptura sociedadhumano/naturaleza - $\tan$ fuertemente presente en las sociedades occidentales- no se encuentra en la cultura campesina santiagueña. Otra construcción central es la concepción del tiempo, que es largo - en comparación con el inmediatismo occidental- y no necesariamente lineal, tiempo en el que está incluida la naturaleza entera y que abarca a les ancestres y también a las generaciones futuras. Finalmente, las herramientas e instrumentos permiten aprender saberes a partir de la interacción con otres seres y construir nuevos, herramientas e instrumentos que, como hemos visto, se basan primordialmente en la observación y en la exploración. Estos tres elementos de la matriz cultural (Cruces, 2008) del campesinado interactúan de forma dialéctica con la praxis de les campesines, que está 
situada en cierto contexto histórico y social. Es en este contexto que la matriz cultural campesina se produce y reproduce (Baraona, 1987).

En estas matrices culturales

está basada la posibilidad de constituirnos como sujetos: saber quiénes somos y cuál es nuestro lugar en el mundo [...] Una lucha particular, dado que el reconocimiento siempre depende de otros tanto como de uno mismo, y vale en la medida en que no se arranca por la violencia. (Cruces, 2008, p. 178)

En un sistema capitalista que tiende a hacer desaparecer al campesinado (Baraona, 1987), estas luchas se observan tanto en los relatos sobre la lucha por la tierra y por el monte y sobre los atropellos de los terratenientes como en los conflictos en las escuelas. No obstante, también las migraciones y los trabajos simbólicos del capitalismo, por alentar la migración del campo a la ciudad - que ha dejado áreas inmensas y pueblos enteros desiertos de gente-, llevan a este resultado. Incluso, las migraciones temporarias pueden tener el mismo efecto, al trastocar las identidades.

\section{Escuela de Agroecología}

En 2007, el MoCaSE-VC - cuando aún no se había reunificado- se planteó la conformación de la Escuela de Agroecología. Es un espacio de formación para la vida en el monte santiagueño, donde una semana al mes se realiza un curso en las instalaciones que el movimiento tiene en la ciudad de Quimilí, en el este de la provincia, durante ocho semanas al año (MoCaSE-VC, 2016). La formación como "Asistente en Producción Agroecológica" -titulación post-primaria- dura tres años. Quienes no hayan terminado la primaria, tienen la posibilidad de realizar un año previo de terminación de dicho nivel, con la misma organización de tiempo, encuadrado en la modalidad de Educación de Jóvenes y Adultes. La reunificación de ambos MoCaSE dio la posibilidad a las comunidades de las sierras de Guasayán de que sus integrantes, mayormente les jóvenes, participen de la Escuela de Agroecología.

La Flaca, referente del área de formación del MoCaSE-VC, comenta sobre la escuela:

Flaca: Pensaba en lo de la Escuela de Agroecología. Nosotros nunca, nunca se nos cruzó esto de una escuela. $\mathrm{Y}$ en esto de ir caminando como movimiento, e ir viendo que los jóvenes se iban sumando a las reuniones, y que en esto de reflexionar juntos, el derecho que no se cumplía de una educación para todos, porque en las comunidades a gatas hay escuela primaria, [...] entonces se sumaban los jóvenes, demandaban, todos demandaban y teníamos el sueño de una educación para todos, con la posibilidad de formarse, la invasión del modelo agroexportador y demás, que no solo estaba destruyendo nuestros territorios sino a veces cuestionando el modelo campesino, y el resultado por ahí en la práctica, económico, también, que decís: “¿Y bueno, por qué no puedo hacer soja?, si la pagan bien a la soja". Entonces llegó el momento en que algunos compañeros largaron sobre la mesa en un secretariado: "Y bueno, y por qué no hacemos una escuela, ¿ipor qué no una escuela de agroecología? Enfocada a los jóvenes, donde podamos reflexionar sobre nuestro modelo de producción campesina, la soberanía alimentaria, el tema de la reforma agraria. Eso, cómo poder formar a nuestros jóvenes, que sigan el camino de la lucha de ustedes. Que no muera el modelo campesino de producción". Y bueno, los compañeros lo planteamos también en la 
duda de si tenía pie y cabeza esto de la escuela. Y hoy después de cuatro años de la escuela vemos que ha sido un golazo, digamos, por todo lo que significó la formación de nuestros jóvenes, el protagonismo que han asumido, el impacto que ha tenido en las comunidades. Ahí sí, creo que sí, que hubo un momento donde dijimos bueno "a ver, toda esta historia, todo esto que hemos estado acumulando, cómo le podemos dar una vuelta”. La escuela era una posibilidad. (MoCaSE-VC, 2017, pp. 66-67)

En reuniones de la Mesa Regional de Tierra Choya-Guasayán, se planteó la posibilidad de que jóvenes de las comunidades participaran de esta instancia y de que habría un trabajo de promoción sobre la escuela en las mismas comunidades, realizado por un grupo de personas organizado junto al MoCaSE-VC.

- E4: La idea con el MoCaSE es que ellos vengan en enero a contar cómo funciona la escuela de Agro y la UniCAM, porque sí quieren trabajar más con los jóvenes en cuanto a la difusión con las escuelas. Y esto, de que nosotros sabemos que cultivamos con una mirada agroecológica, pero ellos te dicen, no solamente es con una mirada agroecológica, sino que también es con todo un contenido social de resistencia de las familias campesinas. Eso es lo que a nosotros nos falta trabajar y ellos lo tienen más trabajado. Así que como tareas que se abren con la unificación de MoCaSE que nosotros no las teníamos y que recién las estamos masticando.

La Escuela de Agroecología tendría, entonces, diferentes dimensiones desde donde se fortalece el modo de vida campesino, entre otras: garantiza el derecho a una educación, forma a la juventud dentro de la organización social y política y para la producción sustentable en sus predios, y busca así disminuir las migraciones. Es una formación para la vida en el monte en oposición a la que construyen las escuelas de los pueblos y en los territorios campesinos. Además, es una formación para la participación en la organización campesina, para fortalecer, a partir de la incorporación de la juventud en distintas instancias del movimiento, al campesinado en sus procesos de disputa con el agronegocio.

\section{Conclusiones}

Como señalan Michi y Matteo (2009), la disputa entre el campesinado y el agronegocio no es por la tierra, sino por la posibilidad legítima de ser campesines o por la existencia y la re-existencia (Domínguez et al., 2006), entre cuyas dimensiones se encuentran la lucha por la tierra, lo productivo y por las formas legítimas del saber y de la recreación de los saberes. El aprendizaje en procesos de participación comunitaria intencionada - las tareas productivas familiares - es una vía para la recreación de saberes ancestrales del campesinado, con formatos muy diferentes al escolar. Es una vía en la que no solo participan niñes y adolescentes, sino también adultes cuando realizan tareas cooperativas con otras personas de la comunidad. Así pueden acceder a otras maneras productivas, ponerlas en práctica, examinarlas y confrontarlas con las propias. La legitimidad del modo de vida campesino es importante colectiva e individualmente para que les jóvenes puedan proyectarse en el futuro individual y colectivo bajo condiciones materiales concretas.

Entendemos que la educación se estaría constituyendo en un espacio en disputa del conflicto ambiental-territorial entre el campesinado organizado en el MoCaSE y agentes del modelo extractivista, del agronegocio y minero. A diferencia de otros estudios donde 
se plantea un abordaje pedagógico de los conflictos ambientales (Canciani \& Telias, 2013; Corbetta \& Sessano, 2018), en este caso observamos cómo el proceso pedagógico en los territorios campesinos está en disputa en el marco de conflictos ambientales que se sostienen allí. El campesinado organizado, al llevar adelante su lucha de diversas maneras - la acción directa y una acción de resistencia en lo judicial y simbólico por evitar ser desalojados; actividades de formación y el trabajo de base y para recrear, fortalecer y visibilizar la cultura campesina indígena; y trabajos en lo productivo para asegurar el ingreso predial de les hijes y así desalentar las migraciones y su permanencia en el territorio del monte chaqueño-, está dando una disputa en el terreno pedagógico en el conflicto ambiental que mantiene desde su propio modo de vida con el modelo del agronegocio, extractivista, no sustentable y desigual.

El conflicto ambiental, al ser una lucha por la propia existencia del campesinado, un conflicto civilizatorio, es sostenido por el movimiento en las tres formas pedagógicas que identifica Palumbo (2016): la forma-escuela otra - con su más clara expresión en la Escuela de Agroecología-, la forma-taller - por ejemplo, en los talleres-capacitaciones productivas - y la forma-movimiento - en las reuniones de comunidades de base, en la defensa del territorio en conflictos de tierra, etc.- . Al implicar una formación sobre el trabajo - de la agricultura campesina-, estas formas permean las tres dimensiones que encuentran Guelman y Palumbo (2015) en procesos de formación para el trabajo desde la educación popular: lo técnico - en cuanto a la formación situada para una agricultura sustentable en el Chaco serrano-, lo político - en el proceso organizativo- y lo subjetivo -en las transformaciones identificatorias de las personas, en su autoestima-.

No es una lucha por cómo el sistema educativo aborda conflictos ambientales que ocurren fuera de él, sino que los conflictos ambientales analizados tienen como una de sus dimensiones y uno de sus espacios en disputa al ámbito educativo, tanto dentro del sistema como fuera de él.

\section{Referencias}

Alba de, A. (1998). Curriculum: crisis, mito y perspectivas. Miño y Dávila.

Ashpa Sumaj (2012). Memorias de los Orígenes de la Central Campesina de Quimilí. MoCaSE-VC.

Baraona, R. (1987). Conocimiento campesino y sujeto social campesino. Revista Mexicana de Sociología, 49(1), 167-190.

Bourdieu, P. (2012). La distinción. Taurus.

Canciani, M., \& Telias, A. (2013). Aportes teórico conceptuales para pensar los procesos educativos en escenarios de conflicto ambiental. Revista del IICE, 32, 111-122.

Congreso de la Nación Argentina (2006). Ley N. ${ }^{\circ}$ 26.206. Ley de Educación Nacional. Buenos Aires, Boletín Oficial de la República Argentina. http://servicios.infoleg.gob.ar/ infolegInternet/anexos/120000-124999/123542/norma.htm

Congreso de la Nación Argentina (2014). Ley N. 26.994. Código Civil y Comercial de la Nación. Buenos Aires, Boletín Oficial de la República Argentina. http://servicios.infoleg. gob.ar/infolegInternet/anexos/235000-239999/235975/norma.htm 
Corbetta, S. \& Karol, J. (2015). De territorios y epistemes en el ejercicio de pensar la América de nuestros días. En P. Blanco (Ed.), Pensar la ciudad y el territorio en Patagonia desde una perspectiva latinoamericana: relaciones de poder conflictos y resistencias (pp. 53-80). Mandala Ediciones.

Corbetta, S. \& Sessano, P. (2018). Apuntes y reflexiones desde el Pensamiento Ambiental Latinoamericano. En I. Dickmann \& C. Battestin (Eds.), Educação Ambiental na América Latina (pp. 220-245 ). Plataforma Acadêmica.

Cruces, F. (2008). Matrices culturales: pluralidad, emoción y reconocimiento. Revista Anthropos, (219), 173-179.

Defago, A., Bender, G., \& Ithuralde, R. (2012). Ambiente, Desarrollo y Sociedad. En DGCyE, Diseño Curricular de la Educación Secundaria orientación Ciencias Naturales - $6^{\circ}$ año (pp. 153-191). DGCyE.

Díaz, M., Ortiz, P., \& Núñez, I. (2005). Interculturalidad, saberes campesinos y educación. El Colegio de Talxcala; SEFOA; Fundación H. Böll.

Domínguez, D., Lapegna, P., \& Sabatino, P. (2006). Un futuro presente: las luchas territoriales. Revista Nómadas, (24), 239-246.

Ferreyra, C. (2012). Cristian Ferreyra Presente! MoCaSE-VC.

Giraldo, O. (2018). Ecología política de la agricultura: agroecología y posdesarrollo. El Colegio de la Frontera Sur.

González, E. (2012). La ambientalización del currículum escolar: breve recuento de una azarosa historia. Profesorado, 16(2), 15-24.

Gramsci, A. (2015). Antología. Siglo XXI.

Gras, C., \& Zorzoli, F. (2019). Ciclos de acaparamiento de tierra y procesos de diferenciación agraria en el noroeste de Argentina. Trabajo y Sociedad, (20), 129-151.

Griggio, P. (2018). La EFA como espacio de disputas. En L. Zóttola (Ed.), Indisciplinados: aproximaciones a sentipensar la investigación (pp. 77-96). Edunse.

Guelman, A., \& Palumbo, M. (2015). Prácticas pedagógicas descolonizadoras en experiencias productivas autogestionadas de movimientos sociales: el principio formativo del trabajo. Revista Interamericana de Educación de Adultos, 37(2), 48-64.

Massarini, A., \& Schnek, A. (2015). Ciencia entre todxs. Tecnociencia en contexto social. Una propuesta de enseñanza. Paidós.

Matteo di, J. (2015). Prácticas pedagógicas en organizaciones sociales: la perspectiva de los educadores populares en organizaciones campesinas e indígenas [Tesis doctoral no publicada]. Universidad Nacional de Luján.

Michi, N. (2010). Movimientos campesinos y educación: el Movimiento de los Trabajadores Rurales Sin Tierra y el Movimiento Campesino de Santiago del Estero-VC. El Colectivo.

Michi, N., \& Matteo di, J. (2009). La tierra es para el que la trabaja y la cuida. Prácticas cotidianas de educación ambiental en el MoCaSE VC [Ponencia]. VI Congreso Iberoamericano de Educación Ambiental, San Clemente del Tuyú. Argentina. 
MoCaSE-VC. (2016). Memorias de los Orígenes de la Central Campesina de Productores del Norte. EdUNLu-MoCaSE-VC.

MoCaSE-VC. (2017). Recorriendo caminos polvorientos. Trabajo de base en el MoCaSE-VC. MoCaSE-VC.

MoCaSE-VC. (2018). Memorias de los Orígenes de la Central Campesina de Pinto. EdUNLuMoCaSE-VC.

Palumbo, M. (2016). Prefigurando una nueva educación: las formas de lo pedagógico. Sinéctica, (47), 1-17.

Plencovich, M., Costantini, A., \& Zucaro, G. (2011). Educación, ruralidad y territorio ¿Vino nuevo en odres viejos? En M. Plencovich \& A. Costantini (Orgs.), Educación, ruralidad $y$ territorio (pp. 17-95). Ciccus.

Rogoff, B. (1997). Los tres planos de la actividad sociocultural: apropiación participativa, participación guiada y aprendizaje. En J. Wertsch, P. del Río \& A. Álvarez (Eds.), La mente sociocultural. Aproximaciones teóricas y aplicadas (pp. 111-128). Fundación Infancia y Aprendizaje.

Strauss, A., \& Corbin, J. (2002). Bases de la investigación cualitativa: técnicas y procedimientos para desarrollar la teoría fundada. Universidad de Antioquia. 